\title{
Surgical treatment of congenital biliary duct cyst
}

\author{
De-chun Wang, Zi-pei Liu, Zhi-hua Li, Da-jiang Li, Jian Chen, Shu-guo Zheng, Yu He, Ping Bie and \\ Shu-guang Wang*
}

\begin{abstract}
Background: It is acknowledged that total cyst excision is a safe and ideal surgical treatment for congenital biliary duct cyst, compared to simple internal drainage. The aim of this study was to determine the optimal operation occasion and the effect of laparoscopy on congenital biliary duct cyst based upon total cyst excision.

Methods: From January 2002 to January 2011, 217 patients were admitted to Southwest Hospital for congenital biliary duct cyst. To determine the optimal surgery occasion, we divided these subjects into three groups, the infant group (age $\leq 3$ years), the immaturity group ( $3<$ age $\leq 18$ years), and the maturity group (age $>18$ years), and then evaluated the feasibility, risk and long-term outcome after surgery in the three groups. To analyze the effect of laparoscopic technique on congenital biliary duct cyst, we divided the patients into the laparoscopy and the open surgery groups.

Results: Among the three groups, the morbidity from cholangiolithiasis before surgical treatment had obvious discrepancy $(p<0.05)$ (lowest in the infant group), and intraoperative blood loss also had apparent diversity $(p<$ 0.05). Furthermore, long-term outcomes (secondary cholangiolithiasis, stoma stenosis and cholangiocarcinoma) showed no significant difference between different groups ( $p>0.05)$.

Similarly, no significant discrepancy was observed in the morbidity from postoperative complications or long-term postoperative complications ( $p>0.05$ ) between the laparoscopic and the open surgery groups.

Conclusions: We conclude that total cyst excision should be performed as early as possible. The optimal treatment occasion is the infant period, and laparoscopic resection may be a new safe and feasible minimally invasive surgery for this disease.
\end{abstract}

Keywords: Congenital biliary duct cyst, Total cyst excision, Laparoscopic resection

\section{Background}

Congenital biliary duct cysts are congenital anomalies of the biliary tree which are characterized by cystic dilatation of the extra- and/or intra-hepatic biliary ducts. The classic clinical symptoms of the cyst are jaundice, right upper quadrant pain, and palpable abdominal masses. Unlike Western countries, the morbidity of congenital bile duct cyst is much higher in Asia [1,2]. Years ago, the primary treatment of cysts was simple internal drainage by cyst-enterostomy or partial cyst excision. However, several serious clinical outcomes, including stomal stenosis, cholestasis, cholangiolithiasis, and even cholangiocarcinoma, led to poor prognosis, and even secondary surgical operation [3]. At present, total cyst excision

\footnotetext{
* Correspondence: sgwang90@yahoo.com

Institute of Hepatobiliary Surgery of PLA, Southwest Hospital, Third Military Medical University, Chongqing 400038, China
}

with Roux-en-Y cholangiojejunostomy is considered to be a safer and more ideal treatment for patients with congenital biliary duct cysts [4]. The surgical approaches depend on cyst clinical typing $[5,6]$, which has been properly demonstrated by imaging findings (Figure 1), such as computed tomography (CT), magnetic resonance cholangiopancreatography (MRCP), endoscopic retrograde cholangiography (ERCP), etc [7-9]. Appropriate management of types I and II choledochal cysts include cholecystectomy, entire resection of the extrahepatic biliary tract with choledochal cyst, and Roux-en-Y cholangiojejunostomy. Resection of the extrahepatic biliary tract is also recommended for type IV cyst. As for type IV cyst, if there are stricture and/or stones in the intrahepatic abnormal biliary duct, and the cysts are confined to one lobe (or segment), hepatic lobectomy may also be considered. Bipolar intrahepatic cysts are 


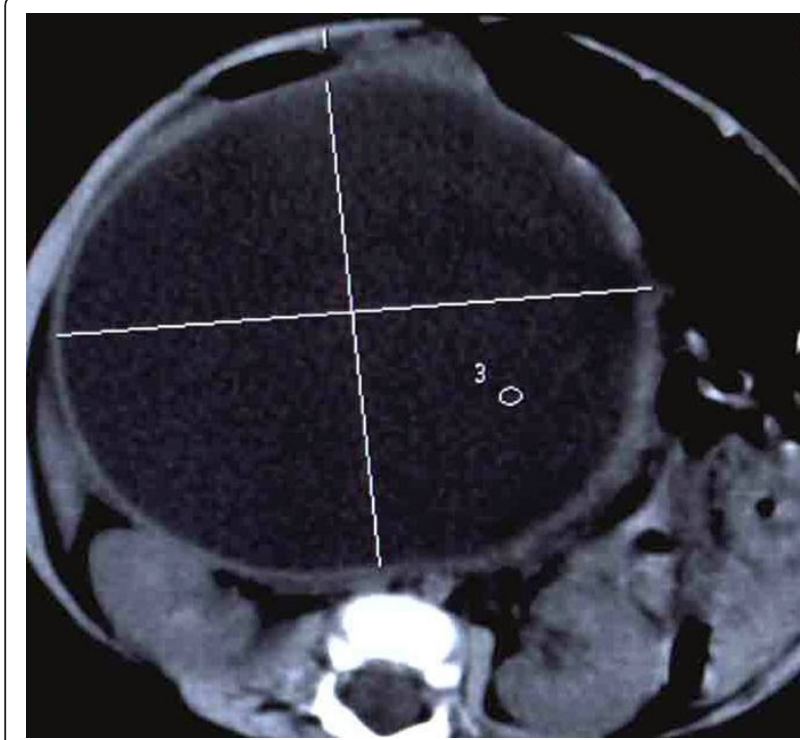

Figure 1 This CT scan shows irregular dilatation of common bile.

associated with a high risk of intrahepatic stones and are managed with long-term transhepatic stenting to provide continuous access to the intrahepatic biliary tree for stone retrieval [2]. The treatment of type $\mathrm{V}$ cyst also depends on its localization [10]. Congenital bile duct cysts are commonly diagnosed in young women (the female to male ratio is $3: 1$ ) [11]. As these patients value the cosmetic results as well as cure of the disease, minimally invasive surgery becomes more prevalent and appropriate. In recent years, laparoscopic resection has been applied for congenital bile duct cysts [12]. The congenital bile duct cysts have a long course of disease, which may lead to increasing morbidity of several complications, including cholestatis, cholangiolithiasis, and even cholangiocarcinoma. However, operation at childhood may increase life-threatening risks. Thus, the best surgical timing for this disease remains controversial.

In the present study, we will investigate the optimal timing of total cyst resection and the effect of laparoscopic technique on the disease.

\section{Methods}

\section{Patients}

From January 2002 to January 2011, 217 patients were admitted to Southwest Hospital, (Chongqing, China) for congenital biliary duct cyst. Demographic data and preoperative status were collected prospectively and analyzed retrospectively. Of the 217 patients, 187 consecutive cases underwent total cyst excision in our hospital. Data were collected retrospectively from a computerized database and analysis of patients' hospital charts. Supplementary information was obtained from standardized telephone interviews with the patients during the followup. This study was approved by the Ethical Committee of Southwest Hospital.

\section{Preoperative evaluation}

Parameters of the hepatobiliary system were evaluated preoperatively, including demography, age, gender, clinical symptoms, biliary complication, localization of cyst, and imaging findings (ultrasonography, computed tomography (CT) scan, magnetic resonance cholangiopancreatography (MRCP), and endoscopic retrograde cholangiopancreatography (ERCP)).

\section{Postoperative management}

All the patients received the same postoperative management by the same team of surgeons. Patients who received surgical treatment were monitored in the intensive care unit (ICU) during the early postoperative period. Subsequently, whether to stay in the ICU depended on the patient's condition.

\section{Surgical treatment}

No type III cyst patient was included in the 187 patients who underwent total cyst excision in our hospital. Treatment of cyst depended on clinical typing. Patients with types I and II cyst underwent total extra-hepatic cyst excision. The division of the biliary tract should be connected to healthy biliary tissues either in the superior or the inferior part of the cyst. Meanwhile, the Roux-en-Y cholangiojejunostomy was also conducted. In this study, the intra-hepatic cysts of types IV and V were localized forms. Thus, patients with type IV cyst also needed total extra-hepatic cyst excision and Roux-en-Y cholangiojejunostomy. If intra-hepatic cysts were localized and complicated with biliary ductal stricture, stones, abscess, or liver atrophy, the partial hepatectomy would be carried out for type IV cysts. Treatment of patients with type $\mathrm{V}$ cyst also relied on the location of bile duct abnormalities. Patients with type V cyst should undergo partial hepatectomy and Roux-en-Y cholangiojejunostomy, if complicated with biliary ductal stricture, stones, abscess, or liver atrophy. Otherwise, they only received Roux-en-Y cholangiojejunostomy.

\section{Follow-up}

All the patients were followed up by the same team of surgeons after the surgery every 2 to 3 months. Ultrasonography, ERCP, or MRCP was annually conducted for stenosis, stone, or even advanced tumor. Patients with stenosis or cholangiolithiasis were treated conservatively if they had no or mild symptoms. Patients with cholangiocarcinoma were suggested with radical resection. If the patients with cholangiolithiasis and severe life-threatening attack of acute cholangitis did not respond to initial conservative 
treatments, other definitive operations should be considered.

\section{Statistical analysis}

Statistical analysis was performed using SPSS 18. If there were 2 or more expectations less than 5 , continuous data would be assayed with Fisher exact test; otherwise, data were analyzed with chi-aquare and $t$ tests.

\section{Results}

The demographic data and preoperative status of the 217 patients are shown in Table 1. Of all the patients, the ratio of female to male was 170: 47 (3.6: 1), and the age ranged from 4 months to 80 years with a mean age of 28.20 years. And the most common symptom was stomachache. Among the patients, 80 had intra- and/or extra-cholangiolithiasis before treatment (Figure 2A-B), and 8 had advanced cholangiocarcinoma (Figure 2C-D).

Total cyst excision should be performed as early as possible, and the optimal treatment time is the infant period

Of 80 patients who had intra- and/or extra-cholangiolithiasis before surgical treatment, 2 belonged to the infant group ( $n=23), 21$ to the immaturity group $(n=58)$, and 57 to the maturity group $(\mathrm{n}=136)$. The three groups showed significant discrepancy $(\mathrm{p}=0.009<0.05)$ in cholangiolithiasis morbidity before surgical treatment. The cholangiolithiasis morbidities in the immaturity and maturity groups were significantly higher than that in the infant group $(\mathrm{p}=0.005<0.05)$; however, no discrepancy existed between the immaturity and maturity groups ( $\mathrm{p}>$ 0.05). In addition, 8 patients had cholangiocarcinoma, of whom 1 belonged to the immaturity group and 7 to the maturity group. However, no significant discrepancy was observed between the three groups $(\mathrm{p}=0.459>0.05)$.

Table 1 Demographic Data and Preoperative Status

\begin{tabular}{ll}
\hline Characteristics & Data \\
\hline Age (years) & $28.2 \pm 18.8$ \\
\hline Gender & $170(78.3 \%)$ \\
\hline Female, n (\%) & $47(21.7 \%)$ \\
\hline Male, $\mathrm{n}(\%)$ & $212(97.7 \%)$ \\
\hline Presenting symptoms & $191(90.1 \%)$ \\
\hline Abdominal pain, $\mathrm{n}(\%)$ & $57(26.9 \%)$ \\
\hline Jaundice, n (\%) & $23(10.8 \%)$ \\
\hline Cholangitis, n (\%) & $161(74.2 \%)$ \\
\hline Type I, n (\%) & $1(0.4 \%)$ \\
\hline Type II, n (\%) & $36(16.6 \%)$ \\
\hline Type IV, n (\%) & $19(8.8 \%)$ \\
\hline Type V, n (\%)
\end{tabular}

A total of 187 consecutive patients underwent total cyst excision for congenital biliary duct cyst in our hospital (Table 2). The youngest patient aged 4 months and the oldest 75 years. Among the three groups, intraoperative blood loss was significantly different $(\mathrm{p}<0.05)$, with the smallest value in the infant group (Table 3).

After the surgery, 153 of 187 patients having undergone total cyst excision were regularly followed up. The visited rate was $81.8 \%$, and the visited duration was 10 to 116 months. There were 10 patients with secondary cholangiolithiasis, 4 with stoma stenosis, and 2 with secondary cholangiocarcinoma. Of them, none of the infant patients $(\mathrm{n}=$ 18) suffered from intra- and/or extra-cholangiolithiasis, stoma stenosis, or secondary cholangiocarcinoma. In contrast, 1 patient in the immaturity group $(\mathrm{n}=46)$ had cholangiolithiasis, and in the maturity group $(n=89), 9$ suffered from secondary cholangiolithiasis, 4 from stoma stenosis, and 2 from secondary cholangiocarcinoma. However, no significant discrepancy existed among the three groups in morbidity from cholangiolithiasis, stenosis or advanced tumors $(\mathrm{p}>0.05)$.

Totally laparoscopic resection may be a new safe and feasible minimally invasive surgery for this disease

Three patients in the laparoscopic group $(\mathrm{n}=22)$ and 14 patients in the open surgery group $(n=165)$ showed postoperative complications. After a long-term follow-up, 13 patients in the open surgery group $(n=136)$ reported secondary cholangiolithiasis, stoma stenosis or cholangiocarcinoma, whereas no patient in laparoscopic group $(n=17)$ reported those diseases. However, no significant discrepancy was observed between the two groups in postoperative complications or long-term follow-up results $(\mathrm{p}=$ $0.668>0.05, \mathrm{p}=1.0>0.05$, respectively).

\section{Discussion}

Internal drainage by cyst-enterostomy or partial cyst excision was once considered the preferred surgical treatment for congenital bile duct cysts. However, its poor prognosis (frequent cholangitis, cholangiolithiasis, and even cholangiocarcinoma) confined its application severely [3]. In recent years, total cyst excision is regarded a more ideal and reasonable treatment for this disease. Our previous study has also confirmed that the total cyst excision has better prognosis than single internal drainage [13]. However, the optimal surgical treatment timing is still controversial.

Congenital bile duct cysts cause abnormal bile duct structure, which is the main factor for cholangiolithiasis and cholangiocarcinoma. The dilated bile ducts cause dilatation-stenosis-like biliary stricture, which subsequently leads to the abnormality of bile dynamics, causing cholestasis and then inducing biliary tract inflammation. In addition, cholestasis could further cause cholangitis and 


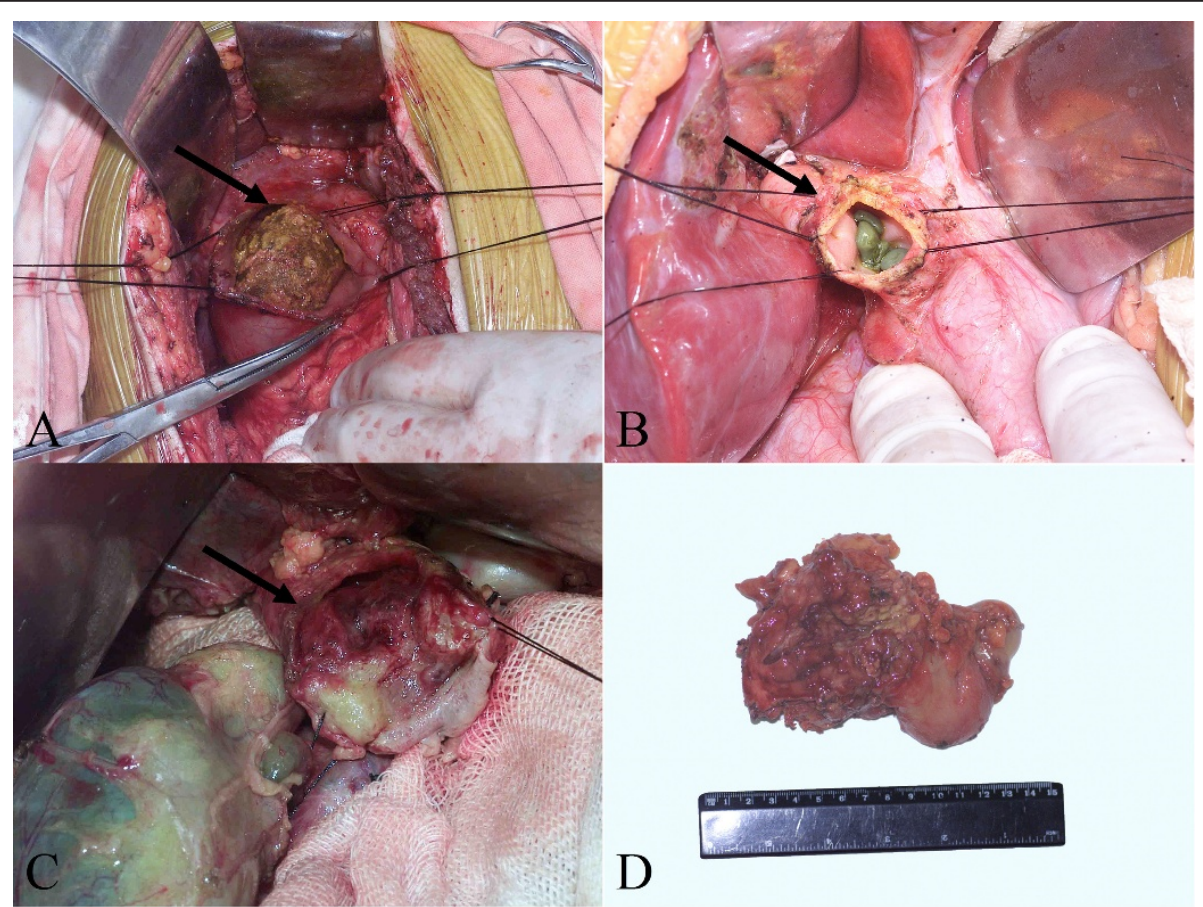

Figure 2 The gross images show the complications of the bile duct cyst specimen. (A-B) These images show stones in the cyst (arrows), (C-D) These images show the cancer of cysts (arrow).

cholangiolithiasis [14], and even cholangiocarcinoma after long-term inflammatory stimulation [15]. The above evidence suggests that the longer the disease course is, the higher the morbidity of complications will be. This study also suggests that obvious discrepancy exists in cholangiolithiasis morbidity among three groups before the surgical treatment. Of all patients, eight suffer from advanced cholangiocarcinoma (the maturity $=7$ and immaturity $=1$ ), which did not arise in infancy. No significant difference was abserved among the three age groups, which may be explained by the limited period of observation.

At present, considering the growth and development of the patients and the surgical risks, most surgeons

Table 2 Basic characteristics of patients underwent total cyst excision

\begin{tabular}{ll}
\hline Characteristics & Data \\
\hline Age (years) & $27.8 \pm 18.2$ \\
\hline Gender & $153(81.8 \%)$ \\
\hline Female, n (\%) & $34(18.2 \%)$ \\
\hline Male, $\mathrm{n}(\%)$ & \\
\hline Clinical typing & $147(78.6 \%)$ \\
\hline Type I, n (\%) & $1(0.5 \%)$ \\
\hline Type II, n (\%) & $28(15.0 \%)$ \\
\hline Type IV, n (\%) & $11(5.9 \%)$ \\
\hline Type V, n (\%)
\end{tabular}

suggest that the infants should not undergo the surgical treatment until they have grown up. However, compared with the adults, the infants have advantages in receiving the surgery. For example, the infants have shorter disease course, which means much milder inflammation and less tissue adherence (Figure 3), which subsequently reduce the probability of hemorrhage and tissue injury, thus lowering the risk of operation. In this study, we have confirmed that the intraoperative blood loss is significantly different ( $\mathrm{p}<0.05)$ among the three groups, and the infant group has the lowest loss. Similarly, our long-term follow-up data have shown that the postoperative complications are not significantly different

Table 3 Intraoperative and postoperative characteristics of patients underwent total cyst excision

\begin{tabular}{|c|c|c|c|}
\hline Group & Infant & Immaturity & Maturity \\
\hline \multicolumn{4}{|l|}{ Intraoperative } \\
\hline Blood loss (ml) & $66.0 \pm 34.2$ & $261.4 \pm 305.6^{*}$ & $389.4 \pm 402.6^{* \#}$ \\
\hline Operation time (min) & $289.0 \pm 70.4$ & $341.2 \pm 104.3$ & $320.0 \pm 120.4$ \\
\hline \multicolumn{4}{|l|}{ Postoperative } \\
\hline Hemorrhage (n) & 0 & 0 & 4 \\
\hline Pulmonary infection (n) & 3 & 0 & 4 \\
\hline Others (n) & 2 & 1 & 7 \\
\hline
\end{tabular}




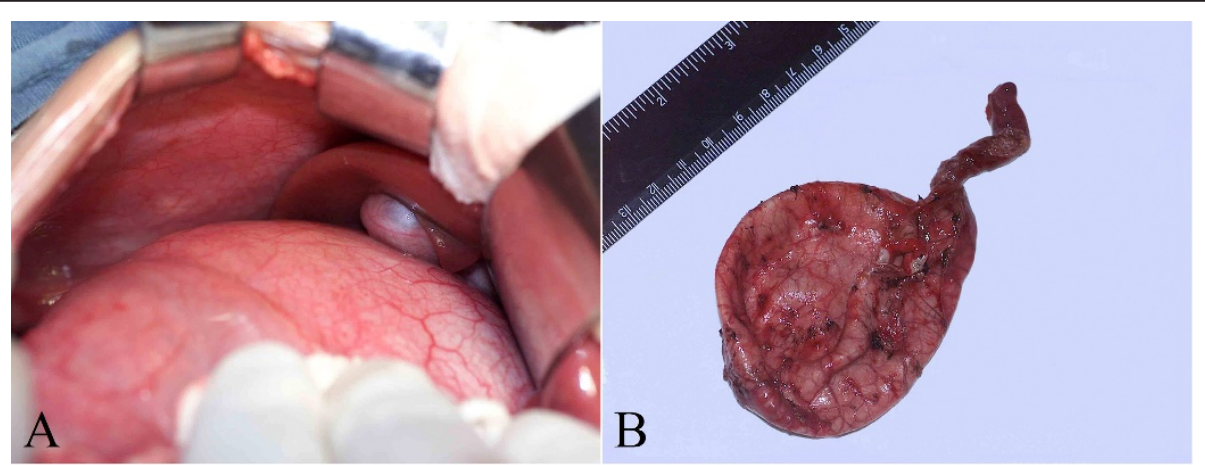

Figure 3 These gross images of the bile duct cyst specimen. (A) The image of the bile duct cyst in operation. (B) The specimen of the bile duct cyst.

among the three groups. The above evidence suggests that the optimal treatment timing for congenital biliary duct cyst is in infancy, which causes the lowest risk. However, our data have shown a significant difference in the postoperative complications among the three groups $(\mathrm{p}=0.012<0.05)$, with the morbidity of postoperative complications in the immaturity and maturity groups significantly lower than in the infant group $(\mathrm{p}=$ $0.036<0.05$ ). Three patients in the infant group have complications. However, these postoperative complications are not lifethreatening and unresolvable, and they may be due to the difficulty in the respiratory management of infants, indicating that preventing pulmonary infection is very important after total cyst excision in infants.

Patients with congenital biliary duct cysts are commonly young women, who value cosmetic results as well as cure of the disease. Thus, minimally invasive surgery is important. To date, totally laparoscopic resection, which is safer and more feasible, has been applied for congenital biliary duct cysts [12] (Figure 4). In addition, the laparoscopic technology can relieve and even eliminate tissue adhesion, and early postoperative pain, and can promote resumption of peristalsis, excellent esthetics, and resumption of activities. Furthermore, our data suggest that no significant difference exists in postoperative complications and long-term outcomes between the laparoscopic and open surgery groups. These findings suggest that totally laparoscopic resection for congenital bile duct cysts is feasible and causes low risk.

\section{Conclusions}

In this study, we domonstrate that the infants with congenital bile duct cyst have lower morbidity of cholangiolithiasis before surgical treatment and lower intraoperative blood loss when undergoing total cyst excision than the immaturity and the maturity groups. In addition, longterm follow-up data indicate that there is no significant difference among the three groups. These findings suggest that total cyst excision should be performed as early as possible, the optimal treatment timing is during infancy, and the totally laparoscopic resection, which is safer and more feasible, may be a new minimally invasive surgery for this disease.

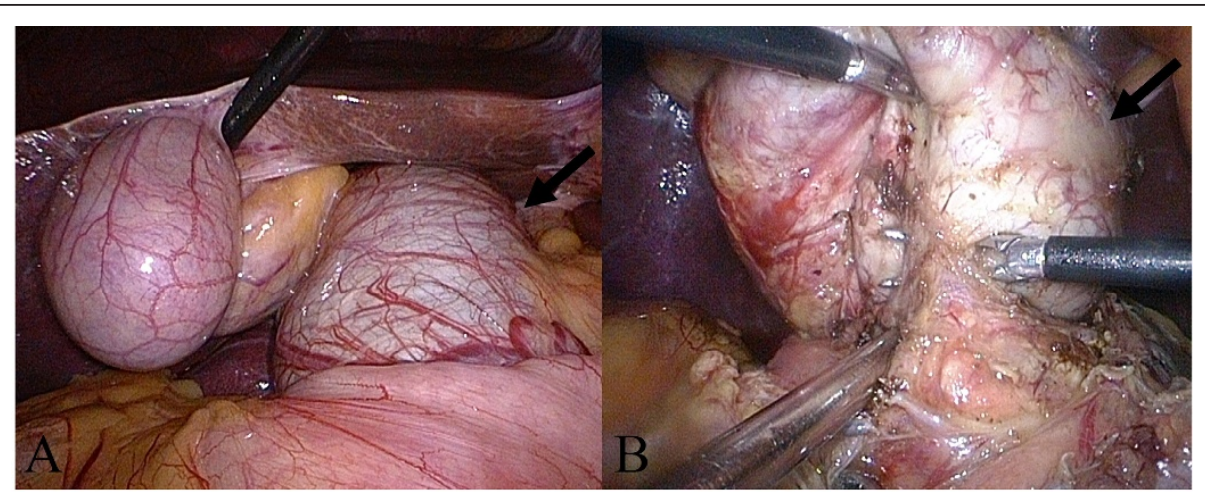

Figure 4 These laparoscopic images show the bile duct cyst specimen. (A) The image of cyst before operation (arrow), (B) The image of laparoscopic resection (arrow indicates cyst). 


\section{Acknowledgements}

We would like to thank Miss Xie-Wan Chen and Ms Xiao-Qing Zhan (Medical English Department, Third Military Medical University, China) for a critical reading of the manuscript and kindly giving precious advice. This work was supported by State Key Basic Research Development Program (2012CB518103), Natural Science Foundation Programs (81130026). This research is also supported by program of New Century Excellent Talents in University (NCET) from Ministry of Education and intramural grants from the State Key Laboratory of Trauma, Burns and Combined Injury.

\section{Authors' contributions}

DW participated in the design of the study, the analysis and interpretation of the data, and drafted the manuscript. ZL participated in the analysis and interpretation of the data. ZL, DL, JC, SZ, YH, PB, and SW performed the surgical procedures, and participated in the analysis and interpretation of the data. In addition, SW also performed the final approval of the article. All authors read and approved the final manuscript.

\section{Competing interests}

The authors declare that they have no competing interests.

Received: 14 December 2011 Accepted: 30 March 2012

Published: 30 March 2012

\section{References}

1. Yamaguchi M: Congenital choledochal cyst. Analysis of 1,433 patients in the Japanese literature. Am J Surg 1980, 140(5):653-657.

2. Wiseman K, Buczkowski AK, Chung SW, Francoeur J, Schaeffer D, Scudamore $\mathrm{CH}$ : Epidemiology, presentation, diagnosis, and outcomes of choledochal cysts in adults in an urban environment. Am J Surg 2005, 189(5):527-531, discussion 531.

3. Todani T, Watanabe Y, Toki A, Urushihara N: Carcinoma related to choledochal cysts with internal drainage operations. Surg Gynecol Obstet 1987, 164(1):61-64.

4. Nagorney DM, Mcllrath DC, Adson MA: Choledochal cysts in adults: clinical management. Surgery 1984, 96(4):656-663.

5. Todani T, Watanabe $Y$, Narusue M, Tabuchi K, Okajima K: Congenital bile duct cysts: Classification, operative procedures, and review of thirtyseven cases including cancer arising from choledochal cyst. Am J Surg 1977, 134(2):263-269.

6. Caroli J, Soupault R, Kossakowski J, Plocker L, Paradowska : Congenital polycystic dilation of the intrahepatic bile ducts; attempt at classification]. Sem Hop 1958, 34(8/2):488-495/SP.

7. Yonem O, Bayraktar Y: Clinical characteristics of Caroli's syndrome. World J Gastroenterol 2007, 13(13):1934-1937.

8. Kim SH, Lim JH, Yoon HK, Han BK, Lee SK, Kim Yl: Choledochal cyst: comparison of MR and conventional cholangiography. Clin Radiol 2000, 55(5):378-383.

9. Lee HK, Park SJ, Yi BH, Lee AL, Moon JH, Chang YW: Imaging features of adult choledochal cysts: a pictorial review. Korean J Radiol 2009, 10(1):71-80

10. Ulrich F, Pratschke J, Pascher A, Neumann UP, Lopez-Hänninen E, Jonas S, Neuhaus P: Long-term outcome of liver resection and transplantation for Caroli disease and syndrome. Ann Surg 2008, 247(2):357-364.

11. Söreide K, Körner H, Havnen J, Söreide JA: Bile duct cysts in adults. Br J Surg 2004, 91(12):1538-1548.

12. Tian Y, Wu SD, Zhu AD, Chen DX: Management of type I choledochal cyst in adult: totally laparoscopic resection and Roux-en-Y hepaticoenterostomy. J Gastrointest Surg 2010, 14(9):1381-1388.

13. Liu ZP, Dong JH, Bie P, Li ZH, He Y, Wang SG: A comparison study of different surgical procedure for congenital cystic dilatation of the bile duct. J Dig Surg 2004, 3(2):84-86.

14. Todani T, Watanabe Y, Toki A, Morotomi Y: Classification of congenital biliary cystic disease: special reference to type Ic and IVA cysts with primary ductal stricture. J Hepatobiliary Pancreat Surg 2003, 10(5):340-344.

15. Edil BH, Cameron JL, Reddy S, Lum Y, Lipsett PA, Nathan H, Pawlik TM, Choti MA, Wolfgang CL, Schulick RD: Choledochal cyst disease in children and adults: a 30-year single-institution experience. J Am Coll Surg 2008, 206(5):1000-1005, discussion 1005-1008.

\section{Pre-publication history}

The pre-publication history for this paper can be accessed here: http://www.biomedcentral.com/1471-230X/12/29/prepub

doi:10.1186/1471-230X-12-29

Cite this article as: Wang et al:: Surgical treatment of congenital biliary duct cyst. BMC Gastroenterology 2012 12:29.

\section{Submit your next manuscript to BioMed Central and take full advantage of:}

- Convenient online submission

- Thorough peer review

- No space constraints or color figure charges

- Immediate publication on acceptance

- Inclusion in PubMed, CAS, Scopus and Google Scholar

- Research which is freely available for redistribution

Submit your manuscript at www.biomedcentral.com/submit
Ciomed Central 